\title{
Incorporation of Artificial Intelligence Tutoring Techniques in Mathematics
}

\author{
https://doi.org/10.3991/ijep.v6i4.6063 \\ Marios A. Pappas, Athanasios S. Drigas \\ NCSR DEMOKRITOS, Institute of Informatics and Telecommunications, Net Media Lab, Athens, Greece
}

\begin{abstract}
Intelligent Tutoring Systems incorporate Artificial Intelligence techniques, in order to imitate a human tutor. These expert systems are able to assess student's proficiency, to provide solved examples and exercises for practice in each topic, as well as to provide immediate and personalized feedback to learners. The present study is a systematic review that evaluates the contribution of the Intelligent Tutoring Systems developed so far, to Mathematics Education, representing some of the most representative studies of the last decade.
\end{abstract}

Index Terms-Artificial Intelligence, Intelligent Tutoring Systems, Mathematics, Intelligent Math Tutors.

\section{INTRODUCTION}

The utilization of new technologies in education has created a learning environment inside or outside the classroom, which allows everyone equal access to education. This new age in education enables learning anywhere and anytime.

Intelligent Tutoring Systems (ITS) apply artificial intelligence techniques in order to construct a learning environment adapted to user needs. The purpose of the Artificial Intelligence is to represent human intelligence, to support communication between the user and the system while problem solving. The goal of the Intelligent Tutoring Systems is to create content that effectively adapts to the knowledge and learning abilities of the learner to optimize learning (Samuelis, L., 2007).

Intelligent Tutoring Systems support diagnostic Assessment in order to detect student's knowledge, misunderstandings and specific tutoring needs. Based on the assessment the ITS are able to select appropriate individualized tasks from a questionbank (VanLehn K. , 2011). ITS in contrast with computer based systems such as CAL (Computer Aided Learning) or CBT (Computer Based Training) adapt to the cognitive profile of the individual pupil and hence develop a model of their skills and expertise (Phobun, P., \& Vicheanpanya, J. ,2010). Furthermore ITS are responsible for providing feedback based on student's errors, hints and tips for each topic, solving strategies step by step for each problem, as well as solved sample exercises.

An Intelligent Tutoring system consists generally of four parts: the Domain Expertise, namely the knowledge of the subject to be learned by the system, the Pedagogical Expertise, which is the control mechanism that guides teaching, the Learner Model, which is responsible to record all relevant information about the student and create an individual learning profile for each one, and the Interface which interacts with the student following the instructions from the Pedagogical model.

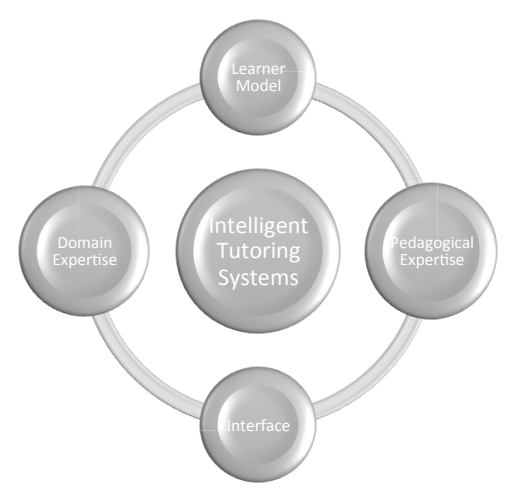

Figure 1. The Components of an Intelligent Tutoring System.

ITS are not intended to replace the teacher, but should be used as a helpful tool in the classroom or as a revision tool.

\section{INTELLIGENT TECHNIQUES FOR INTELLIGENT TUTORING STSTEMS}

\section{A. Rule Based Reasoning.}

Rule Based Reasoning is a particular type of reasoning which uses "if-then" statements. Intelligent Tutoring Systems adopting rule based reasoning use logical connectives such as AND, OR, NOT, e.t.c. in order to form logical functions. The essential components of these systems are the rule base, the inference engine, which uses the knowledge provided by the rule base, the working memory, where the known facts are stored and the explanation mechanism (Prentzas, J., \& Hatzilygeroudis, I. , 2007) There are two kinds of rule based systems, forward chaining, where conclusions are drawn from the initial facts and backward chaining, beginning with a hypothesis (Chen, S. H., Jakeman, A. J., \& Norton, J. P. , 2008)

\section{B. Case Based Reasoning.}

Case Based Reasoning uses examples of problems encountered in the past in order to solve new problems. Case based reasoning systems (Alves, P., Amaral, L., \& Pires, J. , 2008) consist of the following parts:

1. retrieving similar cases experienced in the past,

2. reusing the cases integrating the solutions from the cases retrieved,

3. revising or adapting the solution and

4. retaining the new validated solution

\section{Neural Networks.}

Neural Networks represent a different approach of artificial intelligence inspired by biological neural networks. 
Activation of the network flows from the input layer through the hidden (middle) layer, then on to the output layer (Baylari, A., \& Montazer, G. A., 2009). Each link is associated with weight. The weights of a neural network are determined by a training process with empirical data. The performance of neural networks is also sensitive to the number of neurons (Ding et al, 2013).

\section{Genetic Algorithms.}

A genetic algorithm is usually used as an optimization technique acting simultaneously on a wide set of points. Genetic Algorithms perform a search on the whole area of possible solutions, in order to find the acceptable solution for a given problem. The steps of the algorithm are: initialization, selection, crossover, and mutation (Huang, M. J., Huang, H. S., \& Chen, M. Y., 2007).

\section{E. Constraint-Based Modeling}

Constraint based model tutors use student's errors in order to build a student model represented as a set of constraints infringed or not (Ohlsson, 1994). Each constraint consists of three components: 1) a relevance condition indicating when the constraint is applicable, 2) a satisfaction condition and 3) a feedback message for student's errors (Ma et al, 2014)

\section{INTELLIGENT TUTORING SYSTEMS FOR MATHEMATICS}

\section{A. Problem Solving}

In 2013 D. Arnau et al designed an intelligent tutoring system for the learning of the arithmetical and algebraic way of solving word problems. Hypergraph Based Problem Solver (HBPS) is able to reinforce the translation of a problem into algebraic language or to provide an arithmetical way of solving a problem. The system uses hypergraphs, easy for users to understand, for representation of analytical reading of a given problem, as well as for representation of a solving process, with many alternative resolution paths. HBPS provides also automatic feedback and hints when the user makes a mistake. The results of the experimental study showed that the use of the ITS resulted a significant improvement on the algebraic translation of a word problem.

In 2011 Voskoglou developed a fuzzy AI model for representing several processes in mathematical problemsolving. The construction of this fuzzy model is based on the Multidimensional Problem-Solving Framework (MPSF), including four phases:

$$
\begin{aligned}
& \text { - Orientation } \\
& \text { - Planning } \\
& \text { - Executing } \\
& \text { - Checking }
\end{aligned}
$$

In the experiment which took place at the Graduate Technological Educational Institute of Patras, Greece, 35 engineering students were given a list of 10 word problems to solve. In a second experiment the same list was given to 30 students of the School of Management and Economics. The fuzzy model representing mathematical modelling provides a representative view of the behavior of each student when tackling problems due to the student's individual learning style.

Edwards et al (2010) presented 4MALITY, a webbased mathematics tutoring system, designed to teach mathematical problem-solving skills and test-taking strategies for 4th grade students. 4MALITY adapts to the students' levels of knowledge, by using an Artificial Intelligence decision system. The system's mathematics content is based on the Massachusetts Curriculum Framework. There are four categories of learning styles provided:

- Explain questions in terms of language used.

- Mathematical computational operation.

- Test-taking and problem solving strategies.

- Visual approaches to computation.

\section{B. Algebraic and Arithmetic Operations.}

In 2008, Chien et al evaluated the effect of an intelligent tutoring system on tutoring students on the topic of Algebraic Expression. In the experimental study participated 62 students arranged in two groups, control and experimental. Students of the experimental group Ms Lindquist an ITS based algebra learning software created by Heffernan (2001). After the students choose their current level of algebraic knowledge they are given a problem to solve. The tutoring session of the system uses dialog-based technique to provide students suggestions to perform better in future algebraic problems. The system integrates dynamic scaffolding tutoring strategy, to wit focusing the dialog on the area where the student has difficulty. The teacher can check anytime through the tutoring session the student's performance. The results of the study revealed that the ITS approach was effective in helping students improve their algebraic skills.

In order to compare learner's affect associated with an intelligent tutoring environment and a simulation problem solving game, Rodrigo et al (2008) used Aplusix, an intelligent tutoring system for mathematics (Nicaud, 2006). The system contains activities from six topics based on the curriculum:

- Numerical calculation

- Expansion and simplification,

- Factorization,

- Solving equations,

- Solving inequalities, and

- Solving systems of equations

The student is allowed to solve the given problem gradually, receiving immediate feedback from the tutor as well as guidance to reach the final solution, when needed. According to the results of the study, Aplusix had generally better affect on users than the simulation game.

In their study Graff M., Mayer P. and Lebens M. evaluated a web based intelligent tutoring system for mathematics at German lower secondary schools. Efit uses a subscale of the Heidelberger Rechentest (HRT) in order to assess children's knowledge on basic arithmetic operations, and hence classify them into three categories regarding their educational needs. The efit program provides individual learning curriculum based on the mathematical skills and the learning profile of the student. A sample of 194 students of $5^{\text {th }}$ and $6^{\text {th }}$ grade devided in two groups (treatment and no treatment) was used for the study. The results of the study revealed that students who used the efit program performed significantly better on the post-test than students from the non-efit group. 
Walker, Rummel and Koedinger (2009) had the idea to integrate intelligent tutoring and reciprocal peer tutoring for mathematics learning, in order to investigate how collaborative activities could result to further improvement. The intelligent tutoring system used was Cognitive Tutor Algebra (Koedinger et al., 1997). In reciprocal peer tutoring, students could be placed in the role of tutor, as students of similar algebraic skills are able to communicate and support each other in a chat window during solving. The results of the study revealed that both peer tutors and tutees could benefit from the interaction.

In 2013 Waalkens, Aleven and Taatgen developed an Intelligent Tutoring System for solving linear equations using example-tracing tutors. The system contains 44 first degree equations divided into different levels with respect to the difficulty. The researchers developed three versions of the same ITS, strict standard strategy, flexible standard strategy and multi strategy, which differed in the level of freedom they allow to learners. The intelligent tutor provides solved examples, explanations, feedback messages, next step hints, as well as instructions at the start of each problem set. According to the results of the evaluation study there was lack of strategy variations, as students seemed to stick to the standard strategy.

\section{Fractions and Decimals.}

In 2010, Beal Carole R. et al conducted three studies with middle school students in order to evaluate AnimalWatch, an intelligent tutoring system for arithmetic and fractions. The software was based on artificial intelligence algorithms in order to provide personalized support to individual students. AnimalWatch contain word problems, from easier to more challenging, designed to train user's basic computations and fractions skills. The ITS is able to assess student's skills on each topic and respectively provide useful hints or move on a new math topic. In general the results of the studies encouraged the hypothesis that the ITS software could be a useful and motivating educational tool.

In 2011 N.M. Noh developed an Intelligent Tutoring System for primary school children in the subject of Mathematics, especially in fractions. The objective of their study was to compare the implementation of two different artificial intelligence techniques, rule-based and case-based in the ITS. Rule Based is a particular type of reasoning which uses "if-then" rule statements. The tutor agent of the rule based ITS provides sets of questions depending on the user's progress. The training stops when the user reaches the highest level in the system. In the other hand according to case based reasoning, a given problem could be solved based on the solution of a similar past problem. Case based ITS involve four steps: retrieve, reuse, revise and retain. In order to solve composite problems the system can combine partial solutions.

Rau, M. A., Aleven, V., \& Rummel, N. (2011) designed an intelligent tutoring system for fractions using multiple graphical representations (MRGs). This intelligent tutoring system performs as a cognitive tutor based on correct and incorrect solution paths. The tutors use circles, rectangles and number lines in order to represent graphically fractions. Students are called to compare fractions, reconstruct the unit from unit fractions as well as identify improper and proper fractions. The system provides also error feedback reminding fraction concepts and hints on all steps. The results of the experimental study with 290 participants revealed that there were significant learning benefits for students who worked with a tutoring system that supports learning with MRGs of fractions.

Isotani s., McLaren B. and Altman M. (2010) proposed the development of an intelligent tutor that will use the taxonomy of decimal misconceptions, related to decimals comparison and basic operations, in order to provide a useful learning tool for middle school math students. The erroneous example-based tutor (ErrEx) will present students an incorrect solution of a problem along with a correct one, so that they can learn through the comparison. The tutor also provides feedback with hints and examples to help students understand the concept of decimals.

\section{Geometry}

In 2005 Matsuda and VanLehn proposed an intelligent tutoring system to enhance learning geometry theorem proving with construction. Advance Geometry Tutor starts with a given geometry problem statement and the corresponding figure. The user is allowed to draw line segments on the figure in order to prove the statement. The tutor provides feedback and instructions that the student must follow through the message window. Postulate Browser Window contains a list of postulates which could be used from the student for the proof. Finally the student can see the whole procedure that must be followed step by step to reach the proof on the Inference Step Window.

\section{E. Standardized Tests}

Arroyo I. et al (2010) evaluated the impact of Math Facts Retrieval Training integrated with an intelligent tutor on students' math performance. The Math Facts Retrieval Training software provides assessment and training sections, presenting student's accuracy in progress charts. According to the researchers training speed of math-fact retrieval could improve students' cognitive skills in order to archive greater scores on the math sections of standardized tests such as SAT. The Wayang Math Tutor is an intelligent tutoring system, using interactive multimedia, designed to prepare students' for these tests. Wayang provides immediate feedback on students as well as useful hints adapted to student's individual learning style. According to the experimental results the Math Facts Retrieval Training software combined with the Wayang tutor improved students' performance on standardized math tests, specifically to those with low mathematical skills.

\section{F. Mathematical Logic}

Rosa Lanzilotti and Teresa Roselli (2007) presented Logiocando, an intelligent tutoring hypermedia system developed at the Department of Computer Science of the University of Bari. The purpose of this educational software was to help primary school students to understand basic concepts of logic. The educational content of Logiocando was organized in four topics: sets, set operations and diagrams, providing explanations, logic games and tests for each topic. The system contains a Tutor Module which is responsible for assessing the pupil's knowledge in each topic or show again the theory of the previous. The results of the experimental evaluation revealed that Logiocando could be a substitute of the teacher and be used as a revision tool. 


\section{G. Multi-Task Math Tutors}

Aleven V., McLaren B. and Sewall J. (2009) created an ITS-based open-access web site for middle school mathematics learning. Mathtutor site covers five topics for grades 6 to 8 :

- Numbers and operations

- Algebra

- Data analysis

- Geometry

- Measurement

The system provides step-by-step hints during problemsolving using example-tracing tutors. These tutors are able to evaluate students' problem-solving behavior as well as to provide guidance for multi-strategy problem-solving. Mathtutor, which is an open access site provides also detailed performance data for each student, available to teachers or parents.

Feng et al (2008) proposed an intelligent tutoring system designed to predict student math proficiency. The ASSISTment system is a combination of computer-based tutoring and benchmark testing. If the student solves the given problem correctly, a new problem is given. If the student answers wrong, the system provides a small tutoring session, where the student is given the problem broken into sub-problems in order to reach progressively the solution. According to the researchers the model can do as well as a standardized test.

Keleș, A., Ocak, R., Keleș, A., \& Gülcü, A. (2009) developed ZOSMAT, a web-based tutoring system for mathematics. ZOSMAT is designed to direct students in each stage of learning process using HTML pages, interactive applications, animations, audios and videos. The system supports the generation of adaptive tests, through the questionbank, as well as the analysis of student solutions and errors. The intelligent tutor adapts to individual student's needs, providing examples of problem solving and hints in the process of problem solving. The student can see where more practice is needed on the general report screen or on the topic based report. According to the researchers ZOSMAT is an attempt to imitate the behavior of a human expert tutor.

In 2012 Cabada et al presented Fermat, an Intelligent Social Network for Mathematics Learning. Fermat adopts the traditional architecture, with an Expert Module, a Student Module containing a diagnostic test in order to determine the learning level of the student and the appropriate teaching method and a Tutoring Module where the learner can find problems or exercises to solve, while the solutions given are evaluated in terms of difficulty, assistances, errors and time. The system uses a Genie character to give cognitive and affective feedback to students.

Craig, Scotty D. et al (2013) proposed ALEKS, a webbased learning system with artificial intelligence components, as a method of intervention in after-school settings to improve mathematical skills. The Intelligent Tutoring System administers a test in order to assess student's initial knowledge state. Student can see a summary of his/her learning progress in each topic on a pie chart. Then the student can choose how to continue from a list with problem types he/she is ready to learn. According to the results of the study, 6th grade students who studied using the ALEKS system performed at the same level as students taught by teachers on the Tenessee Comprehensive Assessment Program (TCAP).

\section{CONCLUSIONS}

Intelligent Tutoring Systems could be considered as the new trend in mathematics education. As the studies published in the last two decades revealed, educational systems which adopt artificial intelligence techniques, are not meant to be substitutes of the teacher, but useful supportive or revision tools which can sufficiently imitate a human math tutor.

Most ITS are able to assess students' mathematical skills before they start practice. This process leads to the creation of a personalized intervention program, based on the individual learning profile of each student, in order to achieve the best possible learning outcome. Intelligent tutors have the ability to present the educational material flexibly, using hypertext, audio, video and graphics. Such instruments could be useful in order to encourage children to get involved with mathematics without treat it as another boring obligation.

One of the most important parameters in the design of an Intelligent Tutoring System is the process in which the user solves a math problem. The answers should be given in detail, so that the intelligent tutor can give proper step by step feedback and hints during the whole process of problem solving. In contrast to Computer-aided tools, ITS are able to guide the resolution of more complex math problems.

ITSs can improve students' self-efficacy as well as allow them to explore each topic themselves and learn experimentally solving techniques and math formulas. Despite this, the guidance of the teacher is necessary, as in many cases students can fool the system, not following the instructions of the intelligent tutor correctly, and therefore the learning objective of the system is not reached.

However, ITSs are not yet established as educational tools. Complexity in their design and in their development makes them inaccessible to the general public, and their use is currently limited to universities or major educational institutes.

\section{REFERENCES}

[1] Jean-Fran, cois Nicaud, Denis Bouhineau, Hamid Chaachoua, Jana Trgalova. Developing Interactive Learning Environments that can be used by all the classes having access to computers. The case of Aplusix for algebra. Les Cahiers Leibniz, 2006, 148, pp.1-11. $<$ hal-00190287>

[2] Rodrigo, M. M. T., d Baker, R. S., D’Mello, S., Gonzalez, M. C. T., Lagud, M. C., Lim, S. A., ... \& Tep, S. (2008, June). Comparing learners' affect while using an intelligent tutoring system and a simulation problem solving game. In Intelligent tutoring systems (pp. 40-49). Springer Berlin Heidelberg. http://dx.doi.org/10.1007/978-3-540-69132-7_9

[3] Ohlsson, S. (1994). Constraint-Based Student Modeling. In J. E. Greer, \& G. McCalla (Eds.) Student Modeling: The Key to Individualized Knowledge-Based Instruction (pp. 167-189).

[4] Ma, W., Adesope, O. O., Nesbit, J. C., \& Liu, Q. (2014). Intelligent tutoring systems and learning outcomes: A meta-analysis. Journal of Educational Psychology, 106(4), 901. http://psycnet.apa.org/doi/10.1037/a0037123

[5] Cabada, R. Z., Estrada, M. L. B., Beltr'n, J. A., Cibrian, R., García, C. A. R., \& Pérez, Y. H. (2012, July). Fermat: merging affective tutoring systems with learning social networks. In Advanced Learning Technologies (ICALT), 2012 IEEE 12th International Conference on (pp. 337-339). http://dx.doi.org/10.1109/ICALT.2012.140 
[6] Waalkens, M., Aleven, V., \& Taatgen, N. (2013). Does supporting multiple student strategies lead to greater learning and motivation? Investigating a source of complexity in the architecture of intelligent tutoring systems.Computers \& Education, 60(1), 159-171. http://dx.doi.org/10.1016/j.compedu.2012.07.016

[7] Walker, E., Rummel, N., \& Koedinger, K. R. (2009). Integrating collaboration and intelligent tutoring data in the evaluation of a reciprocal peer tutoring environment. Research and Practice in Technology Enhanced Learning, 4(03), 221-251. http://dx.doi.org/10.1142/S179320680900074X

[8] Voskoglou, M. G. (2011). Fuzzy logic and uncertainty in mathematics education. International Journal of Applications of Fuzzy Sets and Artificial Intelligence, 1, 45-64.

[9] Beal, C. R., Arroyo, I., Cohen, P. R., Woolf, B. P., \& Beal, C. R. (2010). Evaluation of AnimalWatch: An intelligent tutoring system for arithmetic and fractions. Journal of Interactive Online Learning, 9(1), 64-77.

[10] Nicholson, A., Boneh, T., Wilkin, T., Stacey, K., Sonenberg, L., \& Steinle, V. (2001, August). A case study in knowledge discovery and elicitation in an intelligent tutoring application. In Proceedings of the Seventeenth conference on Uncertainty in artificial intelligence (pp. 386-394). Morgan Kaufmann Publishers Inc..

[11] Arnau, D., Arevalillo-Herráez, M., Puig, L., \& González-Calero, J. A. (2013). Fundamentals of the design and the operation of an intelligent tutoring system for the learning of the arithmetical and algebraic way of solving word problems. Computers \& Education, 63, 119-130. http://dx.doi.org/10.1016/j.compedu.2012.11.020

[12] Lanzilotti, R., \& Roselli, T. (2007). An experimental evaluation of Logiocando, an intelligent tutoring hypermedia system. International Journal of Artificial Intelligence in Education, 17(1), 41-56.

[13] Graff, M., Mayer, P., \& Lebens, M. (2008). Evaluating a web based intelligent tutoring system for mathematics at German lower secondary schools. Education and Information Technologies, 13(3), 221-230. http://dx.doi.org/10.1007/s10639-008-9062-z

[14] Matsuda, N., \& VanLehn, K. (2005, July). Advanced Geometry Tutor: An intelligent tutor that teaches proof-writing with construction. In AIED (Vol. 125, pp. 443-450).

[15] Aleven, V., Mclaren, B. M., Sewall, J., \& Koedinger, K. R. (2009). A new paradigm for intelligent tutoring systems: Exampletracing tutors. International Journal of Artificial Intelligence in Education, 19(2), 105-154.

[16] Keleş, A., Ocak, R., Keleş, A., \& Gülcü, A. (2009). ZOSMAT: Web-based intelligent tutoring system for teaching-learning process. Expert Systems with Applications, 36(2), 1229-1239. http://dx.doi.org/10.1016/j.eswa.2007.11.064

[17] Rau, M. A., Aleven, V., \& Rummel, N. (2011). How to Schedule Multiple Graphical Representations? A Classroom Experiment with an Intelligent Tutoring System for Fractions. Society for Research on Educational Effectiveness

[18] Arroyo, I., Woolf, B. P., Royer, J. M., Tai, M., \& English, S. (2010, June). Improving math learning through intelligent tutoring and basic skills training. In Intelligent Tutoring Systems (pp. 423432). Springer Berlin Heidelberg. http://dx.doi.org/10.1007/978-3642-13388-6 46

[19] Noh, N. M., Ahmad, A., Halim, S. A., \& Ali, A. M. (2012). Intelligent tutoring system using rule-based and case-based: a comparison. Procedia-Social and Behavioral Sciences, 67, 454-463. http://dx.doi.org/10.1016/j.sbspro.2012.11.350

[20] Feng, M., Beck, J. E., Heffernan, N. T., \& Koedinger, K. R. (2008, June). Can an Intelligent Tutoring System Predict Math Proficiency as Well as a Standarized Test?. In EDM (pp. 107-116).

[21] Isotani, S., McLaren, B. M., \& Altman, M. (2010, June). Towards intelligent tutoring with erroneous examples: A taxonomy of decimal misconceptions. In Intelligent Tutoring Systems (pp. 346-
348). Springer Berlin Heidelberg. http://dx.doi.org/10.1007/978-3642-13437-1_66

[22] Craig, S. D., Hu, X., Graesser, A. C., Bargagliotti, A. E., Sterbinsky, A., Cheney, K. R., \& Okwumabua, T. (2013). The impact of a technology-based mathematics after-school program using ALEKS on student's knowledge and behaviors. Computers \& Education, 68, 495-504. http://dx.doi.org/10.1016/j.compedu.2013.06.010

[23] VanLehn, K. (2011). The relative effectiveness of human tutoring, intelligent tutoring systems, and other tutoring systems. Educational Psychologist, 46(4), 197-221. http://dx.doi.org/10.1080/00461520.2011.611369

[24] Phobun, P., \& Vicheanpanya, J. (2010). Adaptive intelligent tutoring systems for e-learning systems. Procedia-Social and Behavioral Sciences, 2(2), 4064-4069. http://dx.doi.org/10.1016/j.sbspro.2010.03.641

[25] Alves, P., Amaral, L., \& Pires, J. (2008, July). Case-based reasoning approach to adaptive web-based educational systems. In Advanced Learning Technologies, 2008. ICALT'08. Eighth IEEE International Conference on (pp. 260-261). IEEE. http://dx.doi.org/10.1109/ICALT.2008.197

[26] Chen, S. H., Jakeman, A. J., \& Norton, J. P. (2008). Artificial intelligence techniques: an introduction to their use for modelling environmental systems. Mathematics and Computers in Simulation, 78(2), 379-400. http://dx.doi.org/10.1016/j.matcom.2008.01.028

[27] Prentzas, J., \& Hatzilygeroudis, I. (2007). Categorizing approaches combining rule-based and case-based reasoning. Expert Systems, 24(2), 97-122. $\quad$ http://dx.doi.org/10.1111/j.14680394.2007.00423.x

[28] Ding, S., Li, H., Su, C., Yu, J., \& Jin, F. (2013). Evolutionary artificial neural networks: a review. Artificial Intelligence Review, 39(3), 251-260. http://dx.doi.org/10.1007/s10462-011-9270-6

[29] Huang, M. J., Huang, H. S., \& Chen, M. Y. (2007). Constructing a personalized e-learning system based on genetic algorithm and case-based reasoning approach. Expert Systems with Applications, 33(3), 551-564. http://dx.doi.org/10.1016/j.eswa.2006.05.019

\section{AUTHORS}

Marios Pappas( MA in Inclusive Education student) is a secondary school Mathematics teacher. He is also a research associate at N.C.S.R. Demokritos, Institute of Informatics and Telecommunications, Net Media Lab, Athens, Greece. (marios214@hotmail.com)

Athanasios Drigas is a Research Director at IITN.C.S.R. Demokritos. He is the Coordinator of Telecoms Lab and founder of Net Media Lab since 1996. From 1990 to 1999 he was the Operational manager of the Greek Academic network. He has been the Coordinator of Several International Projects, in the fields of ICTs, and eservices (e-learning, e-psychology, e-government, einclusion, e-culture etc). He has published more than 270 articles, 7 books, 25 educational CD-ROMs and several patents. He has been a member of several International committees for the design and coordination of Network and ICT activities and of international conferences and journals. Also he has accepted several distinctions for his work (articles, projects, patents) (dr@iit.demokritos.gr).

Submitted 20 July 2016. Published as resubmitted by the authors 12 October 2016. 